\title{
High-efficiency and low-environmental impact systems on a historical building in Rome: an InWall solution
}

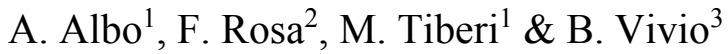 \\ ${ }^{I}$ DIAEE, Dipartimento Ingegneria Astronautica Elettrica ed Energetica, \\ Roma Sapienza, Italy \\ ${ }^{2}$ CITERA, Centro Interdisciplinare Territorio Edilizia Restauro \\ Ambiente, Roma Sapienza, Italy \\ ${ }^{3}$ DISDRA, Dipartimento di Storia, Disegno e Restauro dell'Architettura, \\ Roma Sapienza, Italy
}

\begin{abstract}
The redevelopment of the building system framework can generate a significant impact in an area of great artistic and architectural value as the historical centre of Rome. This paper illustrates the case study of a building located in this particular area of Rome on which the energy consumption and environmental improvements, resulting from interventions such as retrofitting of technological systems, are being evaluated. An integrated design model can resolve issues relating to building maintenance, energy conservation and the integration of renewable energy sources. The study will focus on the identification of high efficiency and low environmental impact systems that are best suited for buildings of historical value placed in complex areas such as town centres. In order to quantify the potential of the proposed solutions, an innovative solution InWall will be illustrated through a specific concept process. The methodology of the proposed project is intended to provide a preliminary approach for the achievement of similar interventions at a large scale. $31 \%$ of Italian buildings were in fact constructed over 65 years ago. Keywords: historical building, retrofitting, wet system building, Building Management System (BMS), smart building.
\end{abstract}




\section{Introduction}

In Italy, $40 \%$ of the houses were built over fifty years ago and now obviously they require maintenance intervention both in terms of restoration and of conformity to the new energy-saving regulations. It should be emphasized, however, that the majority of our housing are historical buildings in terms of urban planning, construction techniques and materials used, but they do not belong to the category of particular interest and value which falls under the protection of the Code of Cultural Heritage (Legislative Decree no. 42, 2004). In Rome, this is true for most of the buildings constructed from 1870 until the Second World War [1][1]. Interventions of plant improvement of historical buildings adopt contradictory practices, as it is customary to operate either applying the full rigor of restoration theory or demolishing buildings without any criteria. It is therefore necessary to launch a cycle of "design-construction management-production industrial/craft applications" which respects the artifacts originally designed during times when the plants components integration was reduced to a minimum. An innovative response to the issues and needs described above can be found in a system which recourse to a technological dry system of interlining components, built-in accessories and high level of compositional freedom [2][2]. The methodology for the design and construction of the InWall, described below, tries to integrate knowledge and technologies (traditional and/or innovative) by seeking concrete solutions in the field of the rehabilitation of existing historical buildings [3, 4][4]. Innovation-Wall, In-the-Wall, Inside-the-Wall, the interpretation of the acronym is intentionally open to a broad definition of the technical solutions that the system in the building process of "system plants-envelope". Can adopt such innovation of integrative building process system, can help to overcome the traditional concept of demolition for the housing of new facilities connected to the production of polluting and often non-recyclable materials, towards a reversible process, upon which a dry interlining technology is based. A technological system based on the assembling of simple innovative lightweight elements framed on a system that is alternative to the traditional "wet" brick-cement mix. In the stratification, the entire wall carries the set of functions required while each component performs a specific function within a system linked to performance, and based on specific project requirements. Technological networks - water, electricity or data - are the components that are most in need of integration into the building sector. The sector of recovery and rehabilitation, where building dry (light weight systems) is a booming market, and not only in the area of new construction, is the subject of an increasing interest by all operators [5][5]. The non-residential building stock is equal to 4.3 million units. 3.4 million are for commercial use, 0.6 million of which are offices [5][5]. 50\% of the Italian service sector consumption is from natural gas and $46 \%$ is from electricity and only $4 \%$ is covered by other sources, which suggests a less intense use of electricity for air-conditioning purposes. It is possible to estimate the consumption of the assets of such buildings. According to ENEA data, offices consume about $120 \mathrm{kWh} / \mathrm{sqm}$ electric and about $90 \mathrm{kWh} / \mathrm{sqm}$ thermal (weighted average of consumption for climate zone). For hotels, this is about $110 \mathrm{kWh} / \mathrm{m}$ electric and about $150 \mathrm{kWh} / \mathrm{m}^{2}$ thermal (as extrapolated from the 
average consumption per room and per destination). The electricity consumption imputable to the basic functions of the building weights, depending on the type of building and the activity that takes place within, is $20 \%$ for offices and $30 \%$ for hotels. The design of energy retrofitting and architectural, especially in historical buildings, must find the best design solutions that provide effective and efficient responses. The project team must have advanced competencies related both to plant-fixture quality level and to sustainability, including historic architectural sensibility [6][6]. Any type of system to be integrated must begin with a design approach that takes as its basis the cognitive aspect of the urban area and building in which it will be inserted [7][7].

\subsection{Historical buildings and integration of fixtures}

The relationship between the fixtures and the building structure can be analyzed and interpreted with an element of social history, that of comfort. Technological innovation in materials and the low cost of production linked to sales has allowed us to make vast leaps in quality of life in terms of interior space. In fact, we have gone from still techniques of building structures and equipment installation networks from the Roman era, through a period marked by the "well-constructed and compliant " economic and housing boom and ending with the current services and functions of the interior spaces served by home automation technology. The innovations that have most affected in the past, and today even more, the change of existing bodies, are those related to the installations for the supply of electricity and heat. In 1877, the first electric generator of alternating electric current was invented, hence the era of electricity for all. The first electrical installations began to appear in this period and pipelines were made primarily with visible tubes or in special protective tubes. The interior design solutions were geared more towards concealed installations in the premises to accommodate both aesthetic and hygienic needs. Plant, hydraulic and electric networks have not undergone major changes until the boom in consumer electronics in the 1970s. Since the late 80 s the rise of the digital era sparked a revolution - still ongoing - transforming electric power plants networks, in which Watt and Bit are deployed and managed from home automation networks (Table 1).

Table 1: Evolution of electrical installations in Italy over the last 150 years.

\begin{tabular}{|c|c|c|c|c|c|}
\hline Second half 1800 & 1970 & 1990 & Domotics & Use & Technology \\
\hline Lighting & Lighting & Lighting & Lighting & Private & Analogic \\
\hline Electric use only & Electric use only & Electric use only & Electric use only & $\mathrm{P}$ & A \\
\hline Telephony & Telephony & Telephony & Telephony & $\mathrm{P}$ & $\mathrm{A}$ \\
\hline \multirow[t]{12}{*}{ Elevators } & Elevators & Elevators & Elevators & Collective & A \\
\hline & TV & TV & TV & $\mathrm{P}$ & A-Digital \\
\hline & Automations & Automations & Automations & $\mathrm{P}$ & A-D \\
\hline & & Air conditioning & Air conditioning & $\mathrm{P}-\mathrm{C}$ & A \\
\hline & & Safety and control & Safety and control & $\mathrm{P}-\mathrm{C}$ & A-D \\
\hline & & Home Entertainment & Home Entertainment & $\mathrm{P}$ & A-D \\
\hline & & & Video control & $\mathrm{P}-\mathrm{C}$ & A-D \\
\hline & & & Sound control & $\mathrm{P}$ & A \\
\hline & & & Manag-Control Elett. Load & $\mathrm{P}-\mathrm{C}$ & A-D \\
\hline & & & Audio-Video Nets & $\mathrm{P}-\mathrm{C}$ & A-D \\
\hline & & & Data nets & $\mathrm{P}-\mathrm{C}$ & $\mathrm{D}$ \\
\hline & & & Net-Metering & $\mathrm{P}-\mathrm{C}$ & A-D \\
\hline
\end{tabular}


This evolution has led to the transformation of electricity networks. More rewiring is required in existing buildings and this has dramatically increased masonry traces. If the new constructions are designed with innovative solutions, with the adaptation of existing buildings, we are at risk of breaking down the layers of wall and interfering with the maintenance of floors and ceilings. The use of BMS systems for the integrated management of plant building components, building automation and supervision software offers a just- in-time management and in real time. A recent study on the Roman heritage buildings has highlighted that the installation of thermostatic valves has the highest index of convenience, in terms of $\mathrm{kWh} / €$ spent, and the shortest payback time compared to more invasive retrofitting interventions [8].

\section{An alternative to invasive approach}

Light wells, niches and tracks in historical buildings, for placing technological networks, is an issue that is not always taken in sufficient consideration by designers and companies. In our opinion, in the building-systems we can define two scales of damage, guided by an "invasive technology". The first, of a cultural nature, is tied to characteristics of the building manufacturing, such as alterations of identity and historical value in the case of heavy work on all elements of the building organism. In this category we can include the building work on facades and other visible parts, but also interventions, even though not obvious, which affect technological units, materials, decorations and construction techniques. The second is linked to the weakening of the supporting structures in natural or artificial stone (such as brick), making tracks, niches and material removals particularly relevant in masonry walls (Fig. 1). Today, in an average apartment of 80 square meters, a standard electrical system under the plaster provided with 60 light points, 7 lines of conduit of $20 \mathrm{~mm}$ diameter reaches a total of 350 linear meters. In existing buildings with structure in solid brick or stone blocks up to approximately 0.65 cubic meters can be removed to create tracks. As a results with depth on the bearing walls that exceed a third of their thickness, without taking into account in this calculation, the electrical switchboard and the junction boxes. It is clear that, by reducing one third to one half of the resistant section of the supporting structures, can endanger the entire structural setting of the building. These interventions are often performed without supervision or control of structure designers.

Such situations should be limited by general static checks, which take into account all the changes occurred on the structure, even in cases of historical buildings not monumental, not subject to public use, on which the regulations allow greater scope for action. In particular, it we refer here to the widespread demands for plant improvement of historical buildings of the late nineteenth century, which are often subject to interventions of functional and technological upgrading with a devastating impact on the nature of the constructive original elements. To have more control of the effects of the intervention, it is appropriate 

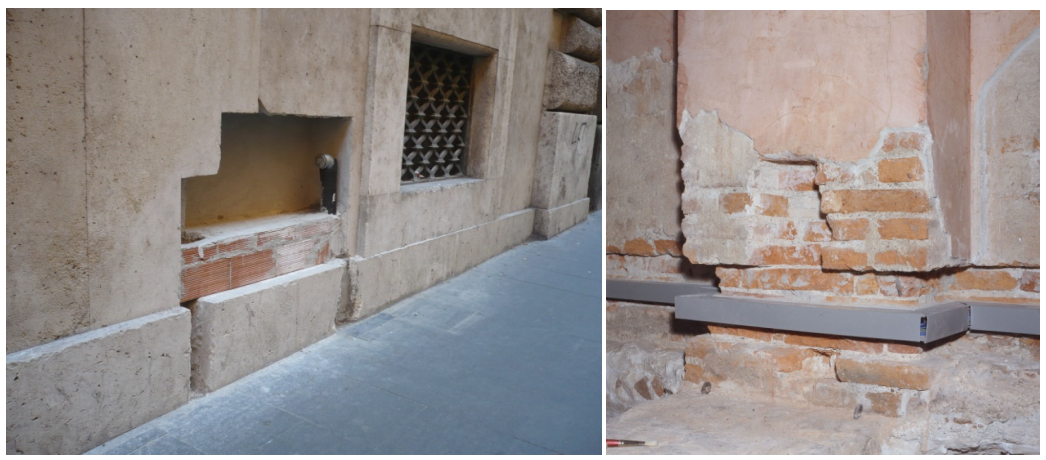

Figure 1: Niche performed on a male wall of a building in the historic center of Rome adjacent to a window. Cut in the walls and in pilasters of Milan's Palazzo Reale for the passage of electrical conduit.

to establish an approach to energy issue using the technologies of the BMS, implementing energy efficiency and maintenance, in historic but "smart" building, ensuring environmental sustainability, comfort for the occupants and the reduction of operating costs The implementation of the BMS generates energy efficiencies technology not only thank to more advanced technologies of control and management. "A growing body of evidence in academic literature demonstrates that there is potential for energy savings due to measures targeting behavior users. Literature suggests that up to $20 \%$ of energy savings can be achieved through different measures targeting consumer behavior" [9][9]. Recently, with regard to the buildings energy efficiency, a new generation of energy and carbon savings technologies was developed. Among these, combined heat and power plants (CHP) represent promising solutions through the use of distributed electricity (DE) generation and waste energy recovery systems. Considering $\mathrm{CO}_{2}$ emissions, $\mathrm{CHP}$ fuelled with hydrogen enriched natural gas blends offer good environmental perspectives [10-12][10] [11] [12].

\section{Features and technologies of the system In Wall}

The prototype In Wall was conceived as a feasibility study able to give an answer to the problems of the requalification of historical buildings, applied to a building located in the historic center of Rome: Palazzo Baleani (Fig. 2).

The approach to the system and energy requalification has been set as technological scheme Plug-and-Play, to provide the prerogatives of conservation, upgrading of the energy efficiency ad reversibility of the interventions with a single solution. The concept has been developed aiming at a high compatibility system, at the integrability of accessories for the exterior finish of interlining, at high compositional freedom that aligns of the container in a conscious way. In a short, an economic system, lightweight, flexible, functional and reversible system. 

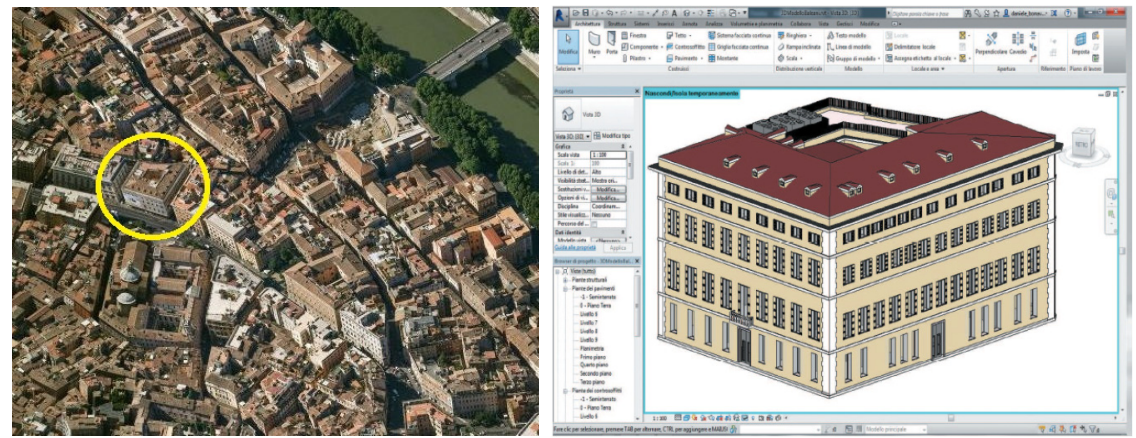

Figure 2: $\quad$ Rome urban area and Revit model of Palazzo Baleani.

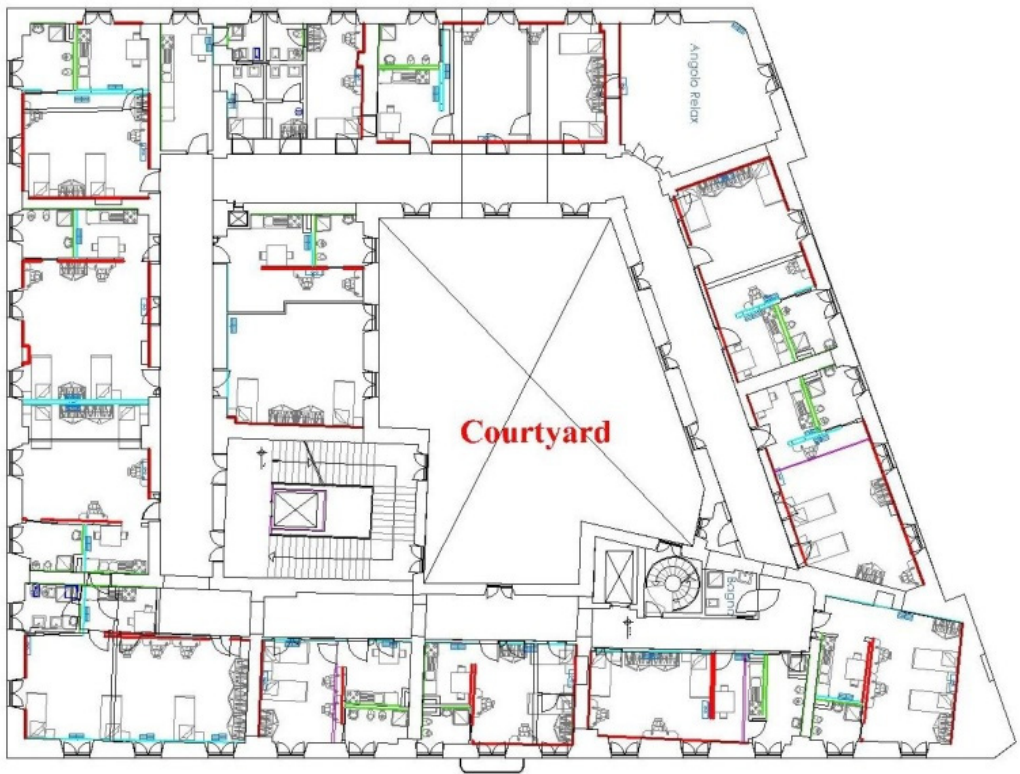

\section{InWall Solution}

Figure 3: Plant of Palazzo Baleani in Rome which shows the new layout of the rooms and the location of the system InWall with the technological networks housed in it.

The more invasive interventions on historical buildings are usually when change the intended use, with prevailing conversion to the tertiary sector, into offices, food services and hotel receptivity, which require solutions conformed to a certain lightness and flexibility. In order to test the prototype In Wall, for the recovery of the interior of Palazzo Baleani a design was initiated for the maintenance of destination for offices use on the ground and first floors and for a 
change of use from office to student house on the second floor (Fig. 3). The threedimensional representation of Figure 4 shows the interlining In Wall in which we highlight the design solutions in technological layers; each of which has a specific function.

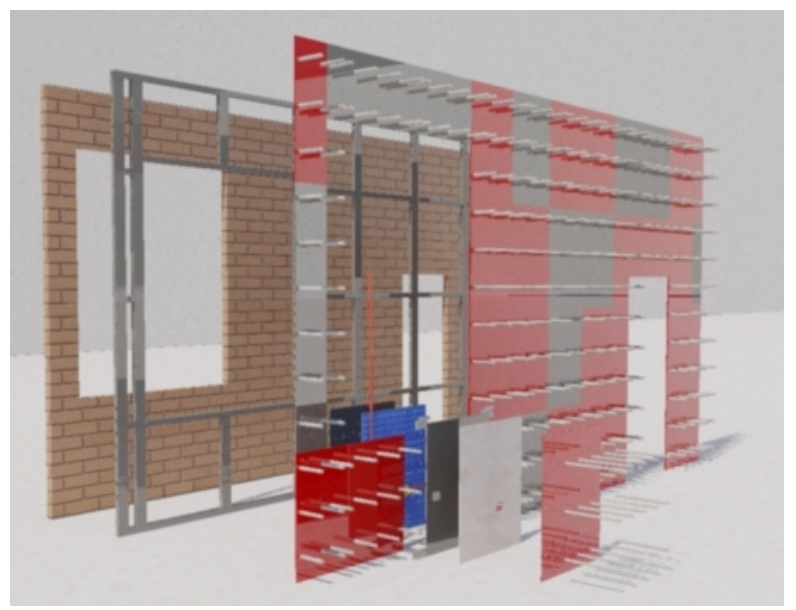

Figure 4: Three-dimensional InWall modular system.

In practice, the prototype intends to test, inside the building process and in the specific instance of the technology of the internal partitions, system solutions that integrate different technological components, such as the electricity grid in low and medium voltage (12-24-220V), infrastructure data with their home automation technology with BUS data transmission, the network for gas (LPG or CNG), water networks and systems for controlled mechanical ventilation (CMV) indoor. The type of multi-purpose building - offices and student house - assumed for Palazzo Baleani, lends itself well to testing solutions In Wall, that adapts to different functions and environments, each with its own their system requirements specifications. On the basis of the performances offered by the present parameters, the materials chosen and the adopted technologies, it has been proposed the realization of an internal wall technology, multi-layer, dry, through the installation of: 1) self-supporting metal structure; 2) technological networks placed on existing walls or modular panels; 3) any air gap for any technical spaces on; 4) different surfaces in exterior finish. Particular attention has been paid to the integration of the self-supporting capacity of chasses and technological networks to be inserted in them (Fig. 5).

In Figure 6 you can see the use of an InWall equipped to accommodate all the systems necessary for the realization of a kitchenette, within a student apartment, planned for the second floor of the building.

The panel leaning against the perimeter wall of the building, has been conceived for the housing of the electrical gas and hydro-sanitary system (Fig. 7), with a minimal sacrifice of the bearing wall on which it stands and with a perspective of a minimum invasiveness for the subsequent maintenance work. In 

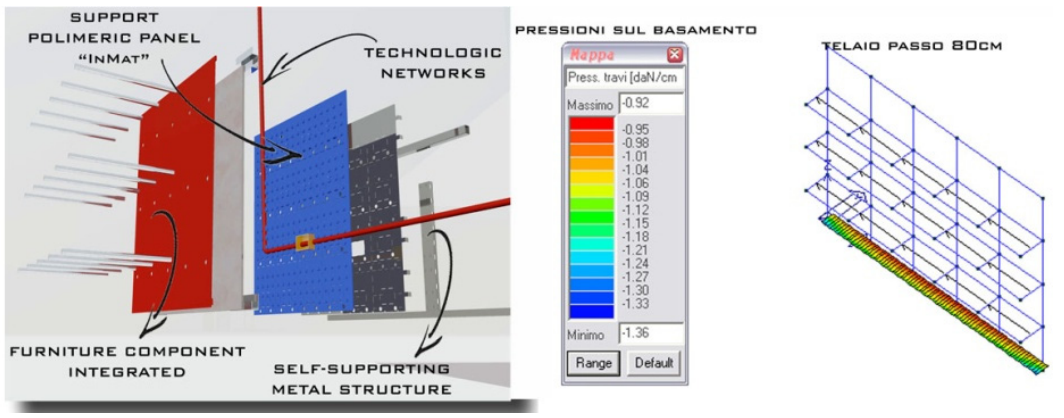

Figure 5: Particular of elements and analysis of the behavior of structures occurred with Pro_SAP_Ry2011.

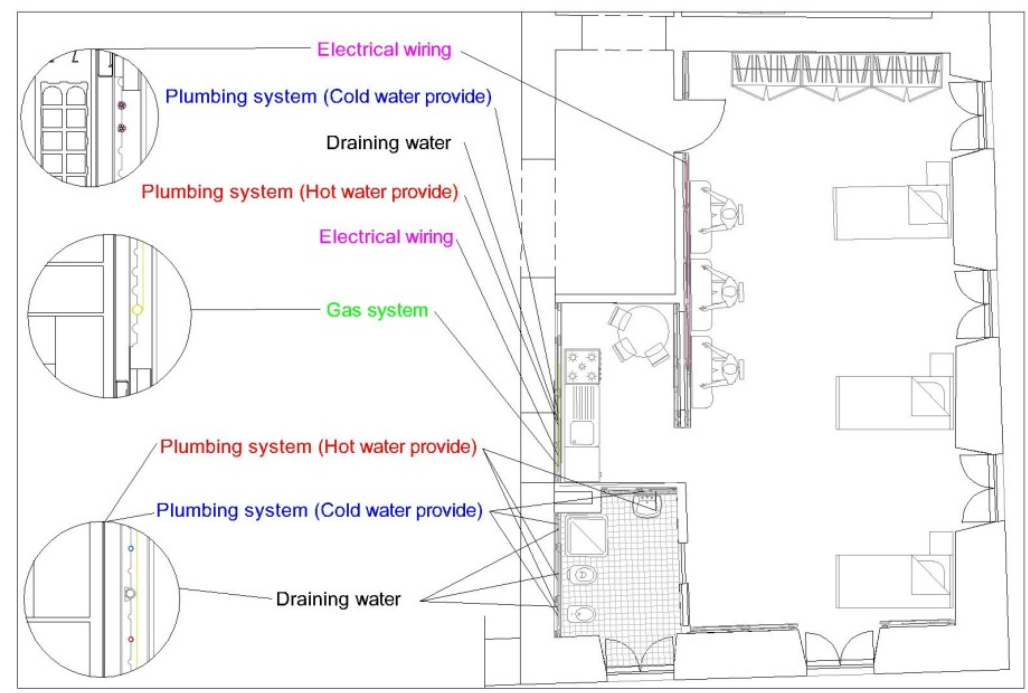

Figure 6: InWall application in a student house.

lightweight and dry systems, technological development has allowed the creation of complexes construction elements, where, in order to satisfy the technical and operational requirements, it has been necessary to superimpose layers of materials with different mechanical characteristics and physical techniques, which are also often deeply different.

In the choice of such components, therefore, it was decided to incorporate furniture components suitable for the characterization of the indoors spaces by "InWall" from an aesthetic and functional viewpoint of: the interlining system, in besides housing the plant networks, was designed by means of suitable freestanding structures (fig. 5) to support large loads of shelves, furniture and electronic equipment. The integration of metal frames and panels of different 
materials functionally optimized (gypsum, wood products, micro-perforated sheets) make easier the realization of separation structures composed of large area and self-supporting. In order to produce self-supporting large surfaces, the integration between the metal frames and dry wall panels (or wood panels) has been realized. The prototype thickness depends on the use required. In particular, if the systems are not present, a $6 \mathrm{~cm}$ thickness is enough. On the other hand, when the electrical and hydro sanitary systems are required, a $10 \mathrm{~cm}$ thickness is needed.

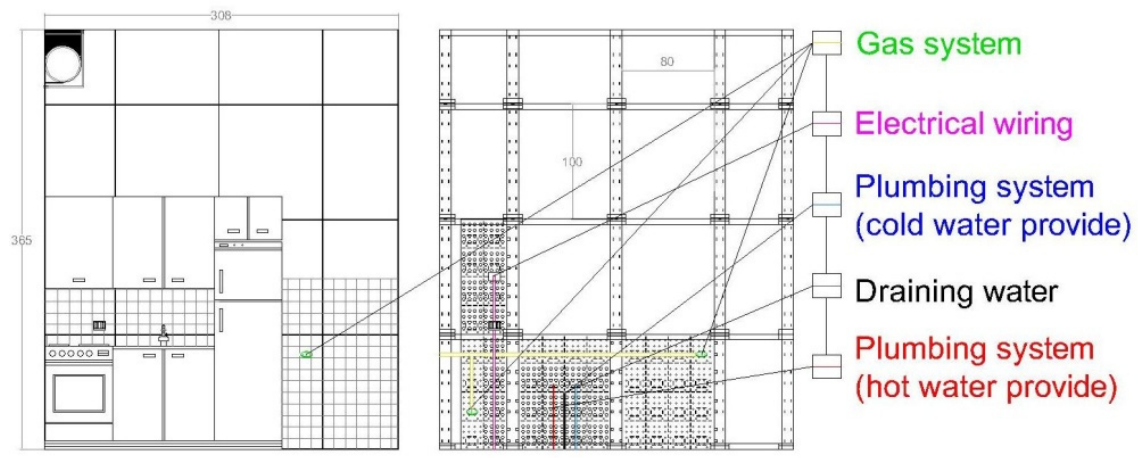

Figure 7: InWall prospect view, system network construction details. Application in a kitchenette.

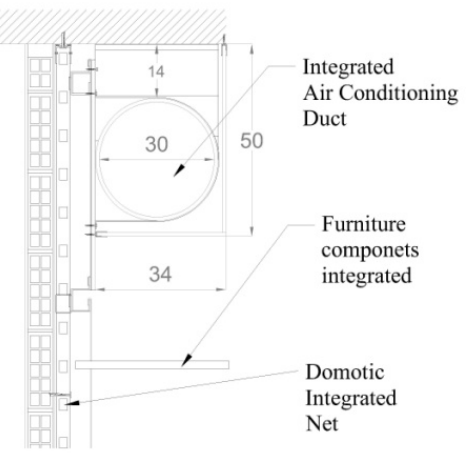

Figure 8: An InWall solution for ventilation insertion: a cross section.

Furthermore, the "InWall" prototype guarantees the air conditioner duct integration as reported in Figure 8 when it is not possible to install it in a suspended ceiling. The relevant characteristics of InWall are the rapidity of execution of interventions compared with the traditional ones (demolition, restoration, finishes, etc.) thanks to its lightness and transportability moreover. Dry construction requires also a reduced number tools. It is minimally invasive as it not involve destructive interventions minimizing openings and traces on masonry structures without affecting the load-bearing capacity. In fig. 16 we highlight the rusticated 
panels form (blue) called InMat that allow you to attach electrical raceways without additional anchors on the wall. This solution is suitable for large-scale interventions with architectural schemes and interior design, such as hotel rooms.

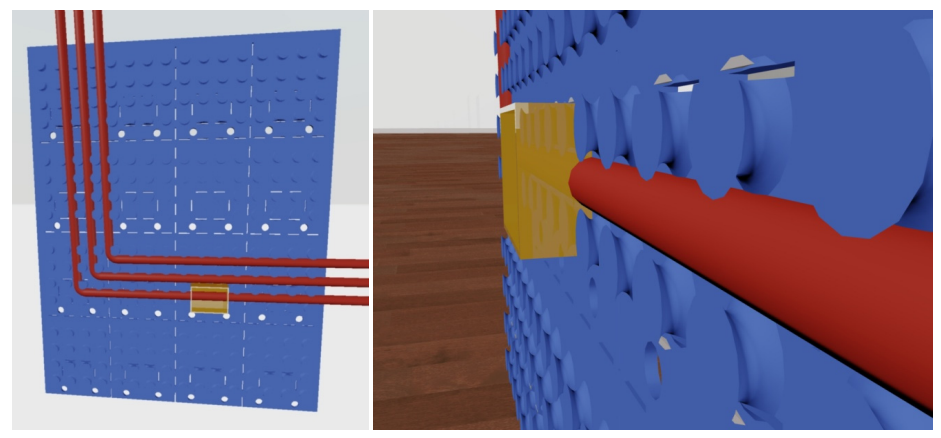

Figure 9: An example of placement of power lines using InMat models.

InMat allows the realization of the systems without altering the existent bottom walls, furthermore it guarantees a negligible reduction of the useful internal space of the building. The InWall system was designed to have a low environmental impact because the selected materials meet the specifications of Life Cycle Thinking. The entire system, from concept to installation, has been conceived with a view of Green Project, which makes use of natural and renewable materials and recycled materials. The materials that make up the system comply with the criteria of the recent product certification standards introduced by the EU Regulation $305 / 11$ for the marketing of construction products. The concept of "InWall" based on the achievement of a high level integration of technology, knowledge and know-how. The solution which provides for the presence of a network of gas transmission, for example, complies with existing sectorial provisions UNI-CIG, but at the same time monitor instruments (sensors) to detect gas leakage connected to the network control home automation (BMS). As regards historical buildings, in particular, system cuts down implementation costs, as the time and costs linked to construction site activities are reduced and spaces may be quickly modified, at a later date, in the case of new needs (indoor spaces configuration).

\section{Conclusions}

The illustrated process design of dry construction system in the field of the historical building retrofitting, can be useful for its wide range of applications with respect to the environment impact on ancient and traditional materials.

The lightness and transportability of the pieces, the opportunity of an integrated control of simultaneous assembly for structural and plants components, makes InWall, and similar systems, an effective alternative to traditional practices, which imply demolition, restoration, and finishes, with consequent reduce costs, due to the easy availability of the materials used and the variety of solutions they can offer. The interior customization and reconfiguration of the historical buildings 
with such a system, results in a significant reduction of destructive interventions on structures. Integration of networks plants with the logical and technological infrastructures of the BMS can transform the active components of a historical building in a node of a Smart Grid. Conceived as part of that construction process which is specific in the redevelopment of historical buildings, InWall system tries to meet both the requirements of adjustment normative, and the conservation and preservation of every single constructive technique. In cases where whole buildings with spans and heights larger than four meters are intended for commercial use, such as offices and shops, InWall system provides a reversible and lightweight approach modifiable, when necessary, in short time, without compromising the sector rules or, structural statics. We have shown how refurbishment on interventions on building-plant are becoming nowadays more and more invasive. Often this approach bypasses the coordination of interventions on the different utility networks and specific installations, resulting in alterations and increase of overall dimensions. Yet issues related to stability masonry supporting structures, too much frequently weakened by ducts, niches and highly invasive interventions, should lead designers, businesses, artisans to adopt best reversible solutions. In historical buildings dating back to 1870 in historical, has it happened in Rome, restorations, retrofitting and various adjustments were realized approximately every 25-30 years. In just 140 years this has happened on four or five occasions. How many of such interventions have been designed and carried out in a reversible and compatible way? Is it possible that an aggressive and invasive approach, that appears to have an exponential trend, may ensure the achievement of class A in energy consumption, in comfort and safety and control of supporting structures for another 140 years?. It appears inevitable that a careful attention should be paid to the compatibility of architectural and energy retrofitting operations to be performed on historical buildings even if they are not bound. Solutions such as InWall can help to validate new perspectives 'compatible retrofitting' of historical buildings which not being classified as museums, have, nevertheless a high historical value. From January 1, 2017 in Italy it will be mandatory to generate at least $27.5 \%$ of domestic hot water and air conditioning from renewable energy sources. Integrating solutions on building-system therefore requires effective and compatible solutions related to all historical building represent. The innovative approach of the process, wants to meet the need of adaptation of historical buildings to the regulations on energy saving in the building sector.

\section{Acknowledgement}

The authors would like to thank Arch. Alessandra Spiniello who took part in the case study.

\section{References}

[1] ISTAT, "Censimento 2012 primi risultati, Popolazione: edifici ed abitazioni a Roma,” ISTAT, Roma, 2012. 
[2] K. Tichelman and J. Pfau, "Costruzioni a secco", UTET Scienze tecniche, Torino, 2009.

[3] F. Cumo, B. Vivio, L. Calcagnini and F. Rosa, "La riqualificazione ambientale degli edifici storici: i tetti verdi", in $67^{\circ}$ Congresso Nazionale ATI, Trieste ISBN: 978-88-907676-0-9, 2012.

[4] F. Rosa, F. Cumo and C. Iviani, "Certificazione energetica applicata al patrimonio edilizio storico: il caso studio di un edificio tutelato", in $8^{\circ}$ Congresso Nazionale CIRIAF, Perugia ISBN: 9788860741806, 2008.

[5] CRESME, "RIUSO 2012," CRESME, Roma, 2012.

[6] F. Rosa and M. Tiberi, "Introduzione alla riqualificazione energetica ed ambientale degli edifici storici: il caso di Roma", Scienza e Tecnica, n. marapr 2013, pp. 8-11, 2013 ISSN: 0582-2580.

[7] F. Cumo, D. Astiaso Garcia, F. Rosa, L. Calcagnini and A. S. Sferra, "Urban policies and sustainable energy management.," Sustainable Cities and Society, vol. 9, pp. 29-34, 2012 ISSN: 2210-6707, doi: 10.1016/ j.scs.2012.03.003.

[8] L. De Santoli, F. Mancini and M. Cecconi, "Energy analysis for retrofitting proposals in Rome residential sector", AICARR Journal, pp. 2-6, Aprile 2010.

[9] EEA, "Achieving energy efficiency through behaviour change: what does it take?" European Environment Agency, Copenhagen, 2013, ISSN 17252237.

[10] L. De Santoli, G. Lo Basso and D. Bruschi, "Energy characterization of CHP (combined heat and power) fuelled with hydrogen enriched natural gas blends.," Energy, no. 60, pp. 13-22 ISSN: 0360-5442, 2013.

[11] L. De Santoli, G. Lo Basso and D. Bruschi, "Hybrid system with an integrated $\mathrm{CHP}$ plant fueled by $\mathrm{H} 2 \mathrm{NG}$ blends: Theoretical energyenvironmental analysis and foreseeable optimizations", Energy and Buildings, vol. 71, pp. 88-94 ISSN: 0378-7788, 2014.

[12] L. De Santoli, G. Lo Basso and D. Bruschi, "Preliminary experimental analysis of a CHP hydromethane system.," Journal of Energy and Power Engineering, no. 7(9), pp. 1681-1690 ISSN: 1934-8975, 2013. 